\title{
A Review of the Research on Film Directors in the 70 Years of New China
}

\author{
Rui Hao \\ School of Theater, Film and Television \\ Communication University of China \\ Beijing, China 100024
}

\begin{abstract}
Since the founding of the People's Republic of China 70 years ago, the research on film directors and the pulse of the times and the development of the film industry have developed together, not only the number of research perspectives increased, but also the horizons has been broaden. This article goes by the following four research categories: historical research, theoretical research, director education, and director criticism, summarize and comment on the literature results of film director research in the past 70 years.
\end{abstract}

Keywords-film director research; history; theory; education; criticism

\section{INTRODUCTION}

In 1921, Lu Jie used the expression "Director George Marshall" for the first time in the introduction of the "Gemstone Case" in the first volume of "The Movie Magazine". Since then, the word "director" has been retained, its function, importance, and core position were gradually established during the changes of the times, technology, and film. And director has become one of the best intermediaries for viewing film creation, image ontology, and its association with culture, art, society, and philosophy.

\section{SEVERAL Stages OF FILM DiRECTOR RESEARCH}

The object of film director research is based on different directors or groups divided by countries, regions, times, factions, styles, backgrounds, etc. The authors of the director research results include the director himself, film practitioner, film manager, film scholar, and other subject scholars, thus bring a variety of research perspectives, including director skills, performance awareness, audio-visual language, narrative analysis based on the director's creative practice; art, aesthetics, philosophy, literature, and cultural studies based on the connotation of the work; personal historical data compilation based on the director individual; cultural geography, comparative analysis, intergenerational inheritance research based on director group, and so on. In general, the film director research since the founding of New China can be roughly divided into three stages.

The first stage is the People's Film Period from the founding of New China to 1977. The political movements led by ideology, the unified cultural context, and the Soviet model of film industry urged the research to move closer to political correctness, resulting in the lack of good results in this period. Therefore, the short-lived contends in this setting are even more precious, especially the articles about the "Director Centered System" and "Necessity of the Art Character of Film" produced after the "Shefan Temple Conference". In addition, the opinions of director creations and film creations by the national leaders and film managers have had a particularly significant impact during this period.

The second stage is the Wave Film Period from 1978 to 2003. The reform and opening up brought about the national economic start, cultural liberation, absorption, collision and avoidance. It also led to the shock of the film system, the market has experienced ups and downs, and the works are unconstrained and all-inclusive, which is quite controversial. At the same time, the film research team in the new era is gradually recovering and growing. Previous scholars engaged in the film translation and some directors became the earliest director researchers. A group of interdisciplinary scholars from literature and history as well as film scholars who have received professional film education have filled the research team and continue to serve as the backbone of film research since the 1990s. The dynamic development of social background, film industry, film works and scholars have laid the embryonic form of director criticism research, that is, from the creation criticism to the extension of culture, aesthetics, history and theoretical criticism, which still in use up to now.

The third stage is the Industrial Film Period from 2003 to the present. With China's accession to the WTO, Chinese film industry accelerated its market-oriented reform and officially entered the industrialization development path in 2003. In 2010, the national box office passed 10 billion yuan for the first time. In the same year, the General Office of the State Council issued the "Guiding Opinions on Promoting the Prosperity and Development of the Film Industry". Large-scale private capital from real estate, Internet and dozens of listed companies replaced the scattered hot money, which stimulate the brutal growth of Chinese film. Contrary to the rapid rise of the film market, filmology has gradually become a famous subject, young scholars have come forth in large numbers, and the number of colleges and universities that have offered film-related majors has increased dramatically since 2002. In 2014, "Internet +" film education flourished, and the talents of filmology has greatly increased, 
the research results also continue to be high-yield. The director research inherits the literary and artistic perspectives of the previous stage, and shows the culture of "looking outward, looking west" to "seeing inward", the return of Chinese culture and film ontology research, and consciously producing the director ecological research with industrialization tendency.

\section{FILM DIRECTOR RESEARCH IN THE HISTORY DIMENSION}

The director research in the history dimension is mainly gradual deepening after the new period. It is divided into collation of original documents and empirical research on this basis; among them the original documents include director's writings, interviews, autobiography, archives, letters, diaries, memoirs, photographs. The original book of the director before the new era is more about the director's elaboration and test criticism, and the "Gan Kai Hua Dang Nian" is one of the few historical works in the "17 years". In it, High-yield Director Yang Xiaozhong recalled the establishment of the Film and Theater Department of the Commercial Press and its production activities, Guan Haifeng wrote "The Film Experience When I shot 'Ten Sisters'". Some of the translations involved the director's diary, such as Iutkevich's "The Man on the Screen", which is also precious material.

After the new period, the original filming work of the early filmmakers and the third-generation directors was carried out with great success, and published "Ying Shi Zhui Huai Lu", "Ying Tan Yi Jiu", "Yin Gai Fan Zhou", "Shanghai film historical materials" and so on. Later, with the opportunity of "rewriting the history of film" and the Chinese film for a hundred years, the compilation will be compiled to a larger volume and extend to more filmmakers and more content, such as "Shi Dong Shan Ying Cun", "Poet Director Fei Mu", these are not only include the director's original works, but also include the memories, evaluations, and comments of the family, colleagues, and friends. In addition, the China Film Archive has been publishing the salvage oral history of the Chinese film "The Series of Oral history of Chinese filmmakers" since 2011, which also provides more bases for the film industry and crossdisciplinary evidence. "The Series of Oral History of Chinese HongKong Filmmakers" published since 2000 by The Hong Kong Film Archive also done the same job.

Secondly, the collation of original documents is also concentrated on the "fourth generation" and later well-known film directors and foreign, Hong Kong and Taiwan filmmakers, especially art film directors, phenomenonal film directors. The monographs published by domestic directors include "Chinese Film Director Series", "My Youth Memoirs", "Jia's thoughts: Jia Zhangke's Movie Notes", "One Mind: Cai Mingliang's Talk on Films" and so on. Most of these monographs are composed of various articles, interviews, and speeches, including the director's life experience, film experience, ideas, etc., as well as the summary of the director's theory. The original record translation of foreign directors was gradually opened up with the deepening of reform and opening up, and was covered by single Soviet director to other countries.

In addition, media evolution has made the original record form increasingly shift from writing to interviewing. If the publication of the "Exploration of Film Director" series and a large number of retelling articles in the 1980s and 1990s with the name of "Visiting $\mathrm{xx}$ director" is golden age of the original writing style, then the new century has been the flourishing of dialogue. "Screen Pursuit: Dialogue with Chinese Contemporary Film Directors" series, "Returning to the Age of Innocence", "Women's Movies: Dialogue with Chinese and Japanese Women Directors", "Driving boat on road: An Interview with Chinese Film Directors in the New Century", "Interview with Chinese Independent Films", as well as the "Dialogue with Felini", "Light and Shadow Language: Interview with Contemporary Chinese Film Directors", "Yang Dechang", "Interview with Top Film Directors" edited by foreign scholars, and a large number of interviews in magazines such as "Contemporary Film", "Movie Art" and "World Movie", "Journal of Beijing Film Academy", have collected the interviews of representative directors in various types. They immediately record the director's thoughts under the anatomy of the times, infiltrating their views toward film, society, ideology, art, realism, philosophy, market and so on.

Based on this, empirical research is regarded as a bridge to bridge the gap between theory and criticism, and is gradually paid attention to since it laid a solid foundation for film research. Its performance has the following points: First, adding relevant historical discourse to contemporary director research can make our research more solid and rigorous. For example: Zhang Chengshan's "Cultural Perspective of Chinese Film - On the Artistic Concepts and Creations of 'Five-generation Directors'" is an early monograph fully review the film composition, aesthetic characteristics, cultural values, pros and cons of intergenerational directors with the combination of history and theory. The subtle analysis of the "Xiren film", "Wenren film", and case studies of the fourth and fifth generations of directors can be said to get rid of the shackles of the literary viewpoint before the 1980s, and lay a good foundation for the increasingly systematic director research. Second, deepen the observation and research of the early filmmakers. In 1997 and 2009, it was the node of two early directors' research and the increase in the proportion of articles. Since 2004, it has been particularly favored by the master's thesis. The results have mainly come from the China Film Art Research Center, the China Academy of Art, Southwest University, Shanghai University, Nanjing University of the Arts and other units. The research focuses on the second generation of directors and some of the third-generation director, radiates abstract ideas and work analysis based on historical materials. Third, the results of combing, recording and summarizing have increased. Such achievements are generally biographical, such as "Collected Biography of Chinese Filmmakers", "Chinese Filmmaker Biography", "Reviewing the Sources of Hong Kong Film Directors in the Past 50 Years". In addition, there are some results that are more distinctive and creative, such as Ogawa Takao in his monograph "History of Post-war 
Japanese Movies"; it uses a quantitative, data-based way to examine the changes in the post-war Japanese film director debut, and the debut chronology of Japanese film directors. A similar approach is the recent research paradigm of film chronology proposed by Li Daoxin. It aims to restore the life course of the characters by supplementing and verifying the objective and detailed chronology of the characters, through the interweaving and dialectic of many chronographs to approach the real history.

\section{DIRECTOR THEORY AND ITS RESEARCH}

The director has a generalized definition that Director is the person who performs the scene scheduling, and also a narrow definition that Director is a complete individual including professional identity. Therefore, the director theory consists of two levels: the systematical and theoretical understanding of the profession of director whose work is scene scheduling; and the collective thinking caused by the director toward the propositions of life, society, politics, literature, religion, aesthetics, etc. The latter is more divergent, and this article only concentrates on the parts related to the film.

In the 1950s and 1960s, "The Translation Series of Film Art" and the China Film Press organized the compilation of the views of Soviet filmmakers and playwrights such as Pudovkin, Eisenstein, Iutkevich, Romm, and Gerasimov, and introduced the modern film theories of Brecht, Bergman, and Tomu Uchida. The representative of domestic China is Zhang Junxiang's "Special Performance Means of Films". He believes that the director should have the dual driving force of image and literature. His later work "Literature completed by means of film expression" highlights his focus on film literature and "Combination of editing with directing". In addition, there are Shi Dongshan's "Some Characteristics of Film Art in Expression", Cai Chusheng's "Some Views on Diagonal Screenplays and Literary Scripts", and Yuan Wenshu's "Characters, Features and Plots in Films", etc. all focus on the elaboration of artistic expressions and methods of film characteristics.

After the reform and opening up, the introduce orientation of director theory was rich and diverse, gradually expand from The Soviet Union and Japan to the new wave of the United States, Britain, France, Germany, Italy and other countries, or to the famous international directors. During that period, the creation theory of art films and commercial films was constructed other than ideological films and main melody films, and the process and elements of film production, and the personal collaboration have been analyzed based on reshaping director's concept. There are also "Hitchcock on Film", Bresson's "Notes on Film Writing", Hu Jinquan's oral version of "Hu Jinquan's Martial Arts Film Practice", Godard's "The History of Film" and other comprehensive theoretical monograph include philosophies, films, symbols, history, art, creation, and execution all together. These film directors have very distinctive style, most of their works are in line with their theory, continue to explore the film issue in mutual correction, and thus become a must-read for research.
Different from the theoretical summary of foreign directors' self-consciousness, domestic directors are not good at large-scale writings. Since the early Chinese films, their views have been scattered in various articles, essays, interviews and lectures. Start with "The artistic declaration of the fourth-generation director" — Zhang Aixin and Li Tuo's "Modernization of Film Language", the industry and academic circles are discussing if we should learn from foreign films and now to learn from then while keeping the film language nationalized, some high-quality papers have been published such as "The film should be filmed", "My Film Concept ", "Only seven years: Exploration and review of middle aged and young directors from 1979-1986". In 1984, the film studio was transformed from a Public Institution into an enterprise, so that they had to operate independently and assumed sole responsibility for its profits and losses. At the same time, the film of "Red Sorghum" was taken, and the fifth-generation director's production ideas were divided, which led to the separation and coexist of the exploration film and the entertainment film. In this regard, the academic circles have discussed the concept definition, commodity attributes, industrial value, audience acceptance, and production mechanism.

After the 1990s, the director's theoretical debates declined, and the theoretical monographs for teaching purposes increased. In terms of articles, directors and scholars have expressed their opinions on specific issues in practice, professionalism, relationship management, and director orientation in the process of marketization.

In summary, the abundant domestic and foreign director theory establishes the basis for the theoretical innovation of the later generations of scholars, and also provides materials for stimulating re-study. Those who paid attention to the early director theory include Tang Jun and his "Theory of Zheng Junli's Early Film Performance Theory", Tian Yizhou and his "'Life is like a Play' - Analysis of Hou Yao's early 'Photoplay' under the Influence of Western Theoretical Discourse". During the "17-year" period, Zhong Dianfei, Shi Dongshan, and Zhang Junxiang's director theories were also taken seriously after the new period. For example, Chen Shan's "Classic Construction: The Maturity of Chinese Film Theory in the 1950s and 1960s", Wang Shaoming, Yu Qiuxia's "The artistic director concept of Mr. Zhong Dianfei". In addition, it includes "On the Academic Achievements and Characteristics of the 'Fourth Generation' Director Group of Beijing Film Academy", "Modern Construction and Reflection of Film Concepts - Debate Research of Chinese Film Concept in the 1980s", which are theoretical reviews of the fourth generation of directors who are most active in developing a voice. What's more, it also contains some reinterpretation of the theory of foreign film directors such as "The Symphonic Orchestra or Accordion - Criticism of Tarkowski's Director Theory", "Gordar: Image, Sound and Politics", "Imagination and Art Spirit: European Film Director Research", "Film Director on Film", "The Theory of Truth: A New Perspective on the Dialectical History of Montage and Long Lens", "A Study of the Aesthetics of Eisenstein's Films" and so on. 


\section{DIRECTOR EDUCATION}

The Directing Department is a major under the film production and creation system, it has the characteristics of teaching benefits teachers as well as students and combining theory with practice together. Therefore, as a branch of director theory research, the academic research results used for director teaching are more focused on explaining the director rules, techniques, and execution methods than the general theoretical writings, assisting with classical directors and film analysis.

Xie Fei recalled the director's education in the 1950s and 1960s and said that the first batch of teachers was composed of young directors from various institutions who graduated from the "director training class" taught by Soviet experts. [2] At that time, there are no special textbooks for learning performances, playwrights, director theory and skills. There are only "The Basic of Film Director" and Stanislavski's monographs, which are lecture notes, outlines or the "Brief Introduction of Film Director" edited by teachers of the department.

The proper and regular director teaching was influenced by the introduction of the British and American director theories and the change of film concept in the new era. The foreign exchange and education reform were strengthened; a group of technical majors focusing on recording and photography took the lead in writing a series of monographs. Wang Xinyu's "Basic Knowledge of Film and Television Directors" started the textbook of director writing in 1987. The book talks about the functions of film directors and the various elements of film. Each part has both the horizontal theory elaboration and the basic theory of law, as well as the vertical application theory with proper examples, so that it lays the basic model of similar works. Since then, there are Zheng Dongtian's "The Artistic World of Film Directors" and Han Xiaolei's "The Artistic Tutorial of Film Directors".

In the new century, the degree of marketization has deepened, and the operation guide type monographs on the production process, experience, and specific practices of the Hollywood film industry have become very popular, "Film Directing Fundamentals", "Film Directing Cinematic Motion", "Directing: Film Techniques and Aethetics" and such books are favored by young directors and film lovers. This kind of monograph featured with simple and easy-tounderstand, focus on real cases not theory, and advance with the times. It decomposed organizational structures, interpersonal relationships, script transformation, directing methods, shooting techniques, creative thinking and judgment criteria, and even gave the topic scope of practical training. Readers can learn the modules in order so that they could build basic audiovisual rules more quickly.

Relatively, the ever-changing market demand, student appeal, and teaching environment are increasingly questioning the gains and losses and the trend of director education. In this regard, there are both retrospective historical research, and the studies evaluate the current director's training system, skills, and the rationality of the curriculum, as well as the intense discussion of identity recognition, director training and teaching models caused by the differences in the image styles of the directors from the Drama Academy and the Film Academy. Among them, Zhang Aigong's article "Film Director Research: The Fight between Image Standard and Drama Standard" argues that only when the film education of the two college systems has formed a relatively complete system and the production of the director group has a common creative style, then the director's distinction can be considered from the educational background. So he turned to a broader and deeper dimension to discuss the style of well-known directors in the history of Chinese film moving from the drama standard to the image standard, but now the rules of the market make the creation of the drama standard a greater advantage, so in the future it will still based on the creation of the drama standard for a long time; Zhao Ningyu detailed the outputs of the directors from "Beijing Film Academy", "The Central Academy of Drama" and other colleges and universities, and argued "At least in the present, the attempt to use universities and colleges to define director style does not have much significance." [3]

\section{DIRECTOR CRITICISM: DECONSTRUCTION, SHAPING, AND DIFFERENTIATION}

The way film directors are talked about and approved is nothing more than a film-based phenomenon commentary or ontological commentary, or both. Put aside the monotonous criticism before the $1980 \mathrm{~s}$, the director criticism methods since the new era include social history criticism, interpretation analysis, comparative analysis, theoretical criticism, image ontology criticism, and ecological criticism of "director-work", covering art, industry, cultural research dimensions. On the whole, the research focuses on deconstruction, shaping, and differentiation, and the relationship in the vertical direction is progressive.

\section{A. Deconstruction}

"Deconstruction" refers to the commentary on the director phenomenon based on the cultural and artistic orientation of the film. The elaboration analysis is a more common essay-style commentary to have a restricted view of director world in the early period of the new era. Another kind of criticism that has gradually become the mainstream of later criticism is to conduct director research with modern film theory and cultural research theory.

First of all, in the 1980s, Chinese films became a grand view and a world-famous voice. The Chinese directors and their work deconstruction attracted the attention of overseas scholars in the perspective of political economy and social history. This style and research paradigm converges with foreign theoretical translations to promote the increase of director's interpretations with structuralism as the methodology. Yao Xiaomeng uses Greimas' Actant Model to analyze some of the films directed by young directors who graduated from the Beijing Film Academy after 1982 in "China's New Movies: Ideological Perspectives". In "The 4th Generation Film Director and Visual Enlightenment", $\mathrm{Hu} \mathrm{Ke}$ also gave up the "Auteur Theory" and adopted Saussure's structuralist semiotics and ideological theory to examine the film language system of the fourth generation 
Television and Chinese Cultural Identity" all have detailed discussions.

3) Modernity and its derived urban-rural relationship, urban culture, post-modern, identity and so on: Representative works include: "On the Cultural Position of Overseas Chinese Film Directors", "The Film Creation of Inter-ethnic Directors Since the 1990s", "Directorship and Urban-Rural Binary Writing of Taiwan Films", "The Paradigm of Minority Film Directors' Ethnic Identity Recognition", "Regional Expression in the Context of Globalization - Interpretation of the Local Consciousness of Chinese Film Directors"; Chen Xuguang's theoretical articles about the fourth, fifth and sixth generations of directors and Modernity issues published in 2004 and 2005; New York University's professor Zhang Zhen's "The Urban Generation: Chinese Cinema and Society at the Turn of the Twenty-First Century"; Ph.D. Thesis "Study on Chinese Ethnic Minority Films during Three Decades since Reform and Opening (1979-2008)", etc.

\section{B. Shaping}

"Shaping" refers to the director's ontological commentary based on the films image, aesthetics, philosophy, and literary dimension. Directors who are more author-like than other contemporary directors will be highly regarded, such as Xie Fei, Xie Tieli, Wu Yigong, Wu Ziniu, Zhang Yimou, Chen Kaige, He Ping, Tian Zhuangzhuang, Jiang Wen, Zhang Yang, Huang Jianxin, Jia Zhangke, Guan Hu, Chinese HongKong and Taiwan directors such like Hou Xiaoxian, Yan Hao, Hu Jinquan, Li Hanxiang, Xu Anhua, Wu Yusen, Du Qifeng, Chen Guo, Wang Jiawei, Li An, Zhou Meiling, foreign directors such like Buñuel, Akira Kurosawa, Truffaut, Bertolucci, Kieslowski, Kitano Takeshi, Abbas, Oliver Stone, Spielberg, Christopher Nolan, Hirokazu Koreeda and so on. Directors from Southeast Asian countries, Nordic countries, Russia, Canada, and South Korea are also gradually introducing into comments.

This kind of research first examines the director's ability to control images. In the 1980s, directors consciously explored a personalized film language system, which is an image combination of long-lens; static lens, color, composition, and sound in order to broke through the plot and to be given aesthetic pursuit. "The imagery of the film and the director's expression - What does the three exploratory films explored?", "The Conflict and Integration of Languages - On the Morphological Changes of $\mathrm{He}$ Ping's Image Expression System" and "Chen Kaige's Director Art Theory" all expressed this process and mechanism in details. The monographs such as "Honour" and "The Studies of the Creative Journey of Worldrenowned Film Directors" are more directly and specifically focused on the narrative ontology of certain film and certain director.

Beyond images studies, the internal aesthetic style, artistic features, and philosophical meanings are examined. This part is almost indispensable in the case study of the director. For example, "Directing Aesthetics on Xie Jin's Films", "China's 'Fifth-generation' Director Encountered 
French film 'New Wave'", "Main Contributions of the FifthGeneration Film to Chinese Film" and other articles vindicated Xie Jin and the Fifth-generation directors who have been strongly criticized and questioned in aesthetics; "Philosophical Observation: Theme and Form - A Preliminary Study of Hou Xiaoxian's Film", "A Preliminary Study of the Structure of Taiwan Film Directors and Their Aesthetic Features", " 'Auteur Theory' and Hu Jinquan", "The Complete Contact of Du Qifeng's Films", "Collage Reality, Clone Dreams - On the Director's Art of Robert Zemeckis" all have a perspective of the thought-world of foreign directors.

As film is a comprehensive art, the basic art types such like literature and drama that make up the film also have a great influence on the director's creation. Taking Zhang Yimou's literary complex as an example, "On Zhang Yimou's Artistic View — from Novel to Film", "Image Wonders and Literary Wand - On the Literary Imagination of Zhang Yimou's Films" talked about Zhang Yimou was keen on screenplays containing Chinese cultural spirit, especially the works that show the Chinese people's past life, with the clue of family/clan, marriage/love/sexuality. But his adaptation is bold and highlights the image standard. The research conclusion of another article "The 'Fifth Generation' and its Film Literature View" is that the "fifth generation" advocates the "marriage" between film and literature in terms of creative tendencies and materials, and the principle of "filming" is adhered to in transplantation or adaptation. This article testifies to the conclusion of the previous article on Zhang Yimou's Film Literature Concept from the perspective of group research.

\section{Differentiation}

"Differentiation" refers to the Research on Director Ecology in the Dimension of Film Industry. With the marketization, industrialization, and securitization three times "Great Leap Forward" [4] of film capital, the composition, concept, creative direction, professional ability, and commercial value of film director are all differentiated and reorganized.

After the marketization route was determined, the fifth and sixth generations of directors and Hong Kong and Taiwan directors who came up north immediately faced the type conversion of creative route. "The Transformation of China's 'Fifth-generation Directors' Cultural Concept from Zhang Yimou's Film" talked about Zhang Yimou, who is the only one who has never experienced the box office failure, is more deeply acquainted with the dialectical relationship between elegance and vulgarity and the commercial and popular nature of the film. And from the 1990s, the "fifth generation" collectively recognizes the cultural concept of the combination of art and business. Under the weight of mass culture, they must make their works close to life and vividly. Similarly, there are "From 'elite Representative' to 'chief Worker' - The Collective Transformation of the Fifth-generation Directors", "The Evolution of the Sixthgeneration Directors — From 'Literature' Film to 'News' Film", "From Cultural Rebellion to Mainstream Market - A Study of the Creation Trend of New Generation Film in
Mainland China" and so on. Relatively speaking, the Hongkong and Taiwan Directors who attracted by the capacity of the mainland market, faced a greater integration problem. Taiwanese directors are more involved in the production of TV dramas, and the scale is much smaller than that of Hong Kong directors. The former Hong Kong film "Tide Rider" Xu Anhua, Xu Ke, Wang Jiawei, Wang Jing, and Ye Weixin have successfully kept up with the film upsurge of martial arts, comedy, the Hong Kong-style Theme Movie after many trails, and then successfully entered the mainland market. But Wu Yusen, Du Qifeng, Er Dongsheng, Peng Haoxiang are increasingly sunk because of the quality of their films is uneven, so they can't always meet the tastes of mainland audiences.

On the contrary, Chen Musheng, Lin Chaoxian, Zhou Xingchi who maintained personal characteristics and promoted the integration of art films and type films, and Guan $\mathrm{Hu}$, Wu Ershan, Ning Hao, Lu Yang, Guo Fan who are known as "New Force" and "New Power", as well as the cross-border directors Xu Zheng, Chen Sicheng, Xue Xiaolu, Han Han have received attention and recognition from the academic circles. Zhang Binning's articles "Type Consciousness, Vision and Industry Standards - Young Director Wu Ershan's Film Prism", "Personality and Standard - Wuershan Film Research in Industrial Context", studied Wu Ershan, who has a professional training and the experience of advertising director, his adaptability of the film industrialization process and the visual differences he presented compare to other directors. Chen Xuguang's "Film Industry Aesthetics", which has been promoted in the past two years, is also inspired by the "New Directors" who adapt to technicalization, industrialization and network survival mode. [5] In addition, "The Cross-border Research of Chinese Film Directors", "The Research on Cross-border Transformation of China's Stars into Directors (2010-2015)", "The Cross-border Directors' Creation Boom from the Perspective of Film Ecology" and other articles continue to follow up and update the cross-border director research.

While cross-border directors are prevalent in reminding the capital heat of the film circle, it also highlights the role conversion, professional constraints and commercial value of the director under the capital, and the profit-seeking logic makes the director gradually become professional and become a brand and symbol. "On the Marketization of Film and the Professionalization of Directors" proposed that the producer-centered system is the only way, and the director should have service consciousness, positioning consciousness, professional ethics and professional skills. "From Professional Logic to Capital Logic: social Network Analysis of the Main Body of Chinese Film Production Based on the Cooperation between Filmmakers and Directors in 2004-2014" verified the return of the role of the producer and pointed out "cross-industry", "cross-border" and collaborative production mechanism is gradually taking shape. The "Director Capital System of Mainstream Films and the Literary Exchange Mode of Film Financing" combined two "central systems" and then proposed "Director Capital System". In addition, "Influential Factors and Empirical Study of Chinese Box Office", "Empirical 
Analysis of the Film Box Prediction Model of Hallywood Film", "Who is More Important, Actors or Directors? - An Empirical Study of the Star Effect of Chinese Film Box Office", "The Influence Research of Fans Economy to Crossborder Director's Film Works" and other articles proved that the influence of director on the mainland market on the box office is the first or second of all factors, and the star director has stronger influence, thus the necessity of director research is also evident.

\section{CONCLUSION}

The above summary doesn't completely summarize the perspectives and representative discussions of all film director researches, but only describes the trends and general outlines of director researches in the past 70 years. In the context of the deepening of Chinese and foreign film creation and academic exchanges, director research will not only be limited to use Grand Theory and Classic Film Theory as methodology, but will also differentiate into more detailed angles aimed at the ever-changing film phenomenon and director phenomenon, so as to solve specific problems or achieve theoretical innovations.

\section{REFERENCES}

[1] Shan Wanli. "Film writing can create nature: Bresson Film Research" $[\mathrm{M}] / / \mathrm{Hou}$ Keming, Du Qingchun. "Imagination and Artistic Spirit: European Film Director Research". Beijing: China Film Press, 2004: 14. (in Chinese)

[2] Xie Fei, Wang Gui. "Director Teaching in the 1950s and 1960s - An Interview with Prof. Xie Fei" [J]. Journal of Beijing Film Academy, 2015(Z1): 17. (in Chinese)

[3] Zhao Ningyu. "Research on the fractions of Film Directors in Colleges and Universities" [J]. Contemporary Film, 2012(2): 49. (in Chinese)

[4] Quan Quanwan. "40 years of Chinese film capital" [EB/OL].(201910-08)[2019-10-16] https://36kr.com/p/5253127?ivk_sa=1023197a. (in Chinese)

[5] Chen Xuguang. "New Era, New Power, New Aesthetics - The current "New Power" Director Group and Its "Industrial Aesthetics" Construction" [J]. Contemporary Film, 2018(1): 32-33. (in Chinese) 